\title{
The Contents and Values of Parts of the Body Related Idiomatic Expressions in Yorùbá
}

\author{
Bolanle T. Opoola \\ The Federal University of Oye, Oye-Ekiti, Negeria \\ Olusegun A. Faniran \\ Kings University, Ode-Omu, Nigeria
}

\begin{abstract}
In this paper, we examine the contents and values of Yorùbá idiomatic expressions that relate to the parts of the human body in social interactions with a view to establishing their communicative value in Yorùbá socio-cultural discourse. A few research efforts on proverbs and idiomatic expressions have studied the scope of their usage in Yorùbá music, the new mode of their usage in political arena and those that relate to Egungun among speakers of Yorùbá language. None, however, have examined the contents of the Yorùbá idiomatic expressions in relation to the parts of the human body. This, therefore, is the preoccupation of the study. Our data for this study comprised thirty purposively selected idioms in Yorùbá language which are used frequently, especially among the elders, in social interactions. The idioms were classified into three domains which captured roughly the major divisions of the human body. The three major parts altogether ensure, in scientific parlance, the homeostasis and viability of the human body. The paper adopted the Ethnography of Communication model as its theoretical framework. Results from the study showed that almost every part of the human body is capable of being used to construct profound and thought-provoking idiomatic expressions which can enhance poetic and rhetoric vigour as well as serve as cultural fillip meant to rekindle the flagging interest of the youths in Yorùbá culture so as to save the Yorùbá language from extinction.
\end{abstract}

Index Terms-idioms, idiomatic expressions, Parts of the Body, Yorùbá Culture, social Interaction

\section{INTRODUCTION}

The human body, according to Wikipedia (https://en.wikipedia.org>wiki>human), 'is the structure of a human being. It consists of the entire structure of a human body which constitutes what is generally termed the parts of the body'. It is composed of different types of cells which ensure, in scientific parlance, body homeostasis and viability. The human parts of the body comprise the head which includes majorly the eyes, the nose, the hair, the lips, the tongue and the teeth. The human parts also comprise the neck, the trunk, the arms, the legs and the feet. Apart from all the aforementioned human parts, there are other organs of the body that lie inside or within the internal human body which are equally vital to human virility. They include: the heart, the lungs, the kidney, the bile, the brain and all other glands of the body as well as the hormones produced by those glands. But, existing research studies into the human body have shown that it is either the exclusive study area of human anatomists and physiologists or the exclusive study area of linguists and language experts with reference to phonology and morphology.

However, none of the previous studies in those areas mentioned have explored the rich linguistic resources inherent in the human body to isolate and explicate the fecund Yorùbá idiomatic expressions which can serve as a fulcrum of intellectual enquiry for the learners of the Yorùbá language, most especially the youths. According to the Oxford Advanced Learner's Dictionary of Current English (2000), 'idioms are a group of words whose meanings are different from the meanings of the individual words'. They are expressions which have figurative and metaphorical meanings. They are conventionally understood by a particular speech community. Idioms, by their nature, hardly ever mean exactly what the words say. In general terms, they are meant to embellish and reinforce expressions in any communication event. In this paper, we argue that almost all of the human organs are a rich source of linguistic discourse in the domain of idiomatic expressions. We argue also that they constitute a veritable tool of linguistic discursive expressions in the explication of Yorùbá ideas and concepts.

\section{Yorùbá Idioms}

The Yorùbá idioms and idiomatic expressions, from ages, have remained a fecund source of the collective wisdom of the elders. They constitute a rich linguistic fountain from which elders in the community draw their salient facts in a discourse. Short and poignant with underlying meanings, idioms are expressions that are natural to a native speaker of a language. Lawal et al (1997) aver that a 'proverb is an idiom of a sort, a tightly condensed representation of a fairly comparable and rather large group of possibilities of socio-cultural experience'. Like the proverbs, idioms have deep and embedded meanings which may, sometimes, sound gibberish, rubbish or like a string of linguistic hocus-pocus to either the non-native speakers of the language or those with a superficial mastery of, or proficiency, in the Yorùbá language. Idiomatic expressions are mostly used by the elders among the Yorùbá people because of their age, vast 
experience and status in the community. This does not imply, however, that the younger ones are forbidden from deploying the rich linguistic artefacts. But, oftentimes, they refrain from using them for fear of inappropriate usage and, consequently, being mocked and reprimanded by their age-mates and the elders respectively.

In addition, Yorùbá idioms are used to complement written or spoken discourse with a view to enhancing the quality of that piece of discourse. For, it is believed that an expression that is lacking in idiomatic expression is like an insipid stew that is lacking in necessary ingredients which otherwise could have given it an exquisite taste. Any expression that is not interspersed with the appropriate idiomatic expression usually sounds bland, insipid and uninspiring like a childish talk. This is why the youths in the Yoruba sub-ethnic group are always encouraged to imbibe the habit of studying Yorùbá idioms so that they can use them to add stylistic felicity to their spoken and written expressions. And, for those who register for Yorùbá as a school subject, they are rigorously drilled by their subject teachers in order that they may be familiar with the usage and meanings of the Yorùbáidioms, and thus, become competent users.

\section{REVIEW OF RELATED WORKS}

Studies on proverbs and idiomatic expressions are many and varied. See Ajayi, Lawal, and Raji,(1997), Salawudeen, (2001), Akanmu,( 2002), Akinmade, (2012), Owomoyela,( 2012), and Adesina, (2015). From those studies, a few deductions can be drawn. First, idioms and proverbs represent the rich source of a people's wisdom and are transmitted from generation to generation. They are part and parcel of the linguistic idiosyncrasies of the traditional African people, most especially the elderly ones. Second, the use of idioms and proverbs forms a part of the discursive strategies employed by the elders to draw home their points. Consequently, idioms are not really peculiar, or restricted to, any particular community, but form an integral part of the speech repertoire among the elders in the Yorùbá sub-ethnic group. Third, they are utilized in day-to-day interactions of Yorùbá elders to communicate social, ethical, cultural and intellectual values which guide and control the lives of those who understand them. Finally, their usage either in speech or in written form is rare or, at best, infrequent, most especially among the up-coming generation of the speakers of Yorùbá language. This is as a result of their exposure to western education and foreign culture. For instance, in his study, Akinmade (2012) laments over the decline in the use of proverbs in the oral expressions among the Ondó people in the southwest part of Nigeria as a result of the influence of western culture on the youths which inhibits the utilization of Yorùbá proverbs among the speakers.

$\mathrm{He}$, therefore, admonishes all stakeholders in the education sector to take the bull by the horns by ensuring that the time-honoured relic of the Ondó people is not thrown inside the dustbin of history. While we empathise, as it were, with Akinmade's (ibid) observation on the declining patronage accorded Ondó proverbs, we, however, want to submit that this discouraging phenomenon is not peculiar to Ondó proverbs alone. Among the speakers of the other Yorùbá dialects too, a glaring absence of the use of idioms and proverbs in the speech and writing of Yorùbá folks is noticeable either when they interact with elders or among their peers or when they write essays in Yorùbá language. It is intriguing to note that whenever they use any of the idioms or proverbs, they tend to use them inappropriately, thus, betraying their gross lack of exposure to the aspect of the rich and fecund Yorùbá socio-cultural heritage.

Similarly, studies carried out by Lawal (1997) and Adesina (2015) examine the use of proverbs within the intellectual ambit of pragmatics. While Lawal (op cit ) study is a pragmatic study of selected pairs of Yorùbá proverbs which focuses at identifying the illocutionary acts performed by the selected proverbs, Adesina's (op cit) focuses on the pragmatic use of some proverbs that are related to egúngún cult among the speakers of Yorùbá language. The egúngún cult, according to him, is one of the notable gods among the Yorùbá whose main preoccupation is to entertain guests at important social events. The use of proverbs that are associated with egúngún in Yorùbá culture, according to Adesina (op cit), 'has become very popular among the Yorùbá and those constructed on egúngún seem to inhabit a variety of spaces in the Yorùbá socio-cultural experience'. Believed to have created a virile and resourceful means of verbal expressions, his study examines the dynamics of constructing proverbs that are associated with egúngún cult whose meanings are beyond their prepositional contents. He, therefore, proposes a purely pragmatic approach to the use and interpretation of the selected proverbs.

Akanmu (2015) also, in his paper, examines the communicative adaptability of proverbs in political discourse. The paper discusses some political issues which utilize new and deviant idioms and idiomatic expressions in a number of socio-political contexts. According to him, the idioms utilized in the paper reflect the dynamism and modernityconstrained stylistic choices in Yorùbá. Motivated by the popular saying that 'the world is a global village' which imposes new global communicative challenges on the Yorùbá people, especially the politicians and their followers and, encouraged by the dynamic characteristic of every language, Akanmu (2015) stresses that Nigerian politicians and their followers have developed novel and rather quaint idioms in their sloganeering repertoire which are worth being given intellectual attention. The study, therefore, is a radical departure from the old traditional method of analyzing idioms. Rather, the study attempts at examining a new trend in the usage of idioms and idiomatic expressions in the domain of politics.

But, our argument is that while the new idioms and idiomatic expressions 'reflect dynamism and modernityconstrained stylistic choices in Yorùbá', they, nonetheless, do not reflect the beliefs and world-views of traditional Yorùbá people in whose mouths the proverbs taste the sweetest. Besides, the new idiomatic expressions which constituted data for his study only represent a reflection of modern-day language use among the upcoming or younger 
generation. None of the studies reviewed above have, as a matter of fact, investigated the contents and values of either the proverbs or idioms that utilize the body parts in social interactions. The present study is significant in the sense that our exploration into the study of parts of the human body reveals that the study of human anatomy and physiology is not to be seen as the exclusive purview of human anatomists and physiologists alone. Rather, it must be considered as constituting a fertile ground on which sociolinguists also can exploit to explicate the communicative and discursive relevance of Yoruba idioms in Yoruba socio-cultural milieu. It is against this backdrop that we consider thirty Yorùbá idioms which are associated with the human organs and show how they are utilized to explicate deep and profound ideas in communication events.

\section{THEORETICAL FRAMEWORK}

This study was carried out within the theoretical construct of the Ethnography of Communication which was propounded by Dell Hymes (1962). The framework studies communication within the ambit of social and cultural practices and beliefs of the particular members of a speech community. It is a theoretical construct which recognizes the intrinsic interface of language and culture. Hymes' (1962) framework accords a high priority to the relation of language to the society as the former cannot be divorced from the latter and, for the latter to thrive, the former is indispensable. In this study, we strongly believe that a deep understanding of cultural norms is necessary for the interpretation of Yorùbá idiomatic expressions as those idioms, by their nature, hardly ever mean exactly what they communicate and thus require native competence to interpret them appropriately.

\section{DATA SOURCE}

The Yorùbá ethnic group belongs to the Niger-Congo ethnic tribe in the southwest part of Nigeria. It is an ethnic group renowned for its vast cultural heritage one of which is the deft use of proverbs and idiomatic expressions which are compact in size, yet so recondite in meaning. Idioms are in a legion, and they are utilized mostly by the elders in the society to embellish and reinforce their speech and writing. Idioms are used by Yorùbá elders in a discourse not only to 'drive their points home' Lawal( op cit), but also to garnish and add stylistic vigour, flavour and vitality to expressions. The idioms and idiomatic expressions that constitute the data for this study were collected from informants who were native speakers of the language since usage of idioms in social interactions is mostly found among them, and, according to Lawal (op cit ), among the Yorùbá, 'proverbs taste sweetest in the mouth of very old people'. Some textbooks on Yoruba idioms and proverbs were also consulted. The data comprised thirty idioms in Yorùbá language with their literal and metaphorical corresponding English language translation. The data were classified into the three major constituent parts of the body namely: the head (and its parts), the trunk (and its parts) and the internal organs which all combine together to ensure the viability of the human body. The data, the usage and the analysis are shown below:

\section{DAta PRESEnTATiOn AND USAge}

This section is devoted to the presentation and usage of our data. The idioms treat such thematic preoccupations as: anger, betrayal, danger, love, destruction, death, anxiety and a host of other psychological and emotional issues that man is confronted with.

\section{A. Idiomatic Expressions That Relate to the Head and Its Parts}

In this section, we examine some idiomatic expressions which relate to the head and its component parts. The component parts include, but are not limited to, the ears, the eyes, the nose, the hair, the lips, the tongue and the teeth. For want of space, we will not be able to explicate all the component parts that constitute the head. The head and its component parts are essential organs in the body, because they give form to the human structure. In other words, without them, human beings remain formless-and, in fact, lifeless. A Yorùbá idiomatic expression which lends credence to the essential nature of the head likens an earless head to a splinter of wood (Etí ò sí, orí dàpólà igi meaning the absence of the ear-lobes from the head has made the head to appear like a splinter of wood). Some of the idiomatic expressions that relate to the head and its parts are discussed below.

1. Forí kólé agbón (Literarily, use the head to collect the hornet's nest but metaphorically, to stir the hornet's nest). It means to be in a serious trouble. This idiomatic expression is used either to warn a person to steer clear of trouble or to make jest of someone who, either through carelessness or stubbornness, has put him/herself in a serious trouble.

2. Gbé àgbondò lówó (Literarily, to hold one's chin but metaphorically, to be idle). The chin, according to the Oxford Advanced Learner's Dictionary (2004), is 'the part of the face below the mouth and above the neck'. It is believed to be a passive organ as it is not classified among the major organs in the human body. Perhaps, because of its passive or not too prominent function it plays in human physiognomy, its usage in Yorùbá cosmology conjures idleness, passiveness and inaction. So, when someone is described as holding the chin with their hands, such a person is being referred to as having been idle, inactive or indolent. Such occasions when the idiomatic expression may be used include, but not limited to, the off-peak period at work-place or during any of industrial action periods like picketing and sit-down strike moments. Such occasions demand that the workers ignore workplace rules and regulations, abandon their duties and 
throw the workplace into a state of disarray. Similarly, the idiom is used to refer to a jobless person who only watches helplessly the unfolding events of life.

3. Fori gbári (Literarily, to knock one's head with another person's but metaphorically, to be in contest with someone). This idiom is used when someone is in a struggle to gain control or power with someone else. It is also used when some contestants are slugging it out with others in a competition such as: beauty, writing, sporting or political contest. The English translation is given as locking horns together or to be at logger heads.

4. Gbontí nù (Literarily, to shake off the ear-lobes but metaphorically, to fail to heed warning). It is used to express complete disregard to something or to treat something as unimportant. Other synonyms in this category include: Koti igboin si and Feti pa laba. In this context, eti (the ear drum) which is the human organ for hearing is used. This means that the ear which is used for hearing may be used to incline to warnings or to ignore warnings as exemplified in the above idioms.

5. Kárí bonú (Literarily, to hide one's head but metaphorically, to bury one's head in shame/sorrow). The head is an easily recognizable part of the body. In human anatomy, the head is at the top of the human body. It carries the trunk, the arms, the legs and the feet. So, when the head which is supposed to occupy the front and easily recognizable position is now buried down, it means that a reproach or a matter of shame is involved.

6. Lù lógo епи (Literarily, to hit someone's mouth with a rod but metaphorically, to laud someone). The underlying or metaphorical meaning of this idiom is incongruous with its ordinary, denotative meaning. The expression, Lù lógo enu, from its primary or literal context of use, gives the picture of a person being hit in the mouth with a rod. So, it is possible for someone who is not a competent user of Yorùbá idiomatic sayings to interpret the above idiomatic expression as meaning that the referent is being struck in the mouth with a heavy object. But, the metaphorical or secondary higher level interpretation of the idiom is far from its denotative meaning. The expression, Lù lógo enu, is understood by every competent user of the Yorùbá language to mean: to praise or to commend someone for a worthy or laudable effort. The expression is, therefore, used to laud, eulogize or extol a good deed performed by someone.

7. Fimú finlè (Literarily, to use the nose to sniff the ground but metaphorically, to investigate). The idiom means to carry out surveillance on someone or to investigate, especially a crime. The nose is positioned beneath the eyes and its major function is to breathe as well as to sniff for something. When the latter meaning is meant, as we have it in this context, an act of surveillance or intelligence report is involved.

8. Fètè òkè lu todò(Literarily, use the upper lip to hit the lower lip but metaphorically, engage in a conversation/talk). The lips constitute an essential part in the human body. They are two: the lower and the upper lips. They are the two soft edges at the entrance of the mouth. They function prominently in the articulation of certain consonant sounds. The idiomatic expression, fètè òkè lu todòcan be used in two different contexts: positive and negative. When the Yorùbá affirm the upper lip 'hits' or articulates with the lower lip, it implies an oral communication, in the form of conversation or discussion, has taken place. The idiom can also be applied to an instance of chattering when the two lips are engaged ceaselessly as in, for instance, two children or two housewives chattering away or at each other in an exited manner. Conversely, when there is no engagement or articulation of the upper and lower lips, a state of complete silence is connoted

9. Korò ojú sí (Literarily, to show bitterness with the eyes but metaphorically, to express annoyance or anger with somebody). The human eyes are two organs on the head which human beings see with. As important organs in the human body, the eyes construct different discursive strategies. They can be used, for instance, to connote anger, warning, pleasantness or to fix a tryst. The idiomatic expression in this context connotes a state of annoyance at somebody for an act of misdemeanour or wrong-doing. In other words, the idiom is applied when a feeling of smouldering anger is expressed to someone for a certain misdeed. It can also be used to express utter indignation or displeasure at, for instance, ill-treatment or unfair dealing in some business transaction.

\section{B. Idiomatic Expressions that Relate to the Trunk}

Our data in this section comprise idioms that relate to the trunk. In human anatomy, the head is believed to attach to the trunk. According to human anatomists, the appendicle portion of the human body consists of limbs, the arms and the legs (see: https://www.pulib.sk>web>subor.1). Essentially, most of the parts comprising the trunk are used for locomotion. The idiomatic expressions below are drawn from parts of the human body of which the arms, the legs and the hands play major roles.

1. Jin lésè (Literarily, to hit on the leg but metaphorically, to betray): This idiomatic expression means to betray someone, to defraud or to behave insincerely or dishonestly to others. The expression can be better understood with some examples from the Holy Bible. For, in the Holy Bible (Gen, chapter 25 verses 24-34) Jacob, the twin brother of Esau was referred to as a traitor and a betrayer because he was believed to have betrayed his twin brother on three different occasions. At birth, the Bible recalls that while Jacob was given birth to, after the birth of Esau, he (Jacob) was said to have taken hold of Esau's heel (Gen. 25: 26), hence, Jacob the betrayer. All the activities of Jacob throughout his life pointed to his treacherous and traitorous instincts. One of such was when he made Esau sell his birthright on a platter of pottage (see Gen. 25: 27-34). Another occasion was when he fraudulently stole the blessings meant for his twin brother-Esau (see Gen. 27: 18-40). The expression, therefore, is used to describe an act of betrayal, conceit, conspiracy and mischief. 
2. Pàkùró lójúgun (Literarily, to crack the palm kernel nuts on someone else's shin but metaphorically. to display wickedness to someone). The shin is a part of the human body at the front of the leg below the knee. The portion in the human body is scarce of the flesh because a thin layer of flesh covers the shin bone. This, therefore, makes the pain excruciatingly felt when someone hits it against an object. The pain is more excruciatingly felt when, out of sheer wickedness, a person decides to hit his fellow human being on the shin with a striking object. The expression is used to describe or state a wicked act; for, it is sheer wickedness for someone to crack the palm kernel on the shin of another person. It is only someone whose sense of humanity or feeling is completely dead that can behave wickedly and cruelly to other people. The idiomatic expression is therefore used to refer to a devilish, godless, vicious and vile person.

3. Fowó rogi igbàgbé (literarily, to hang onto a forgotten tree but metaphorically, to be dead or forgotten). This idiomatic expression is used for a dead person. When a Yorùbá person euphemistically wants to refer to a dead person, he says that the deceased has hung on to a forgotten tree. Other synonyms for the expression include:Gbèkuru je lówó épora (To collect mashed bean cakes from the spirits), Papò dà (Change position) and Wàjà (enter the ceiling). All of the expressions are euphemism of death. The idiomatic expression is heavily embedded to hide meaning from the young folks, especially when the death of an elderly person is announced.

4. Gbe nígbònwósókè or Gbe ní ìunpá sókè (Literarily, to lift someone up by the elbow but metaphorically, to assist especially, with finance). The lexeme, igbònwó or igunpáin Yorùbá means elbow. The elbow is an important part in the human body. According to the Oxford Advanced Learner's Dictionary of current English (2000), an elbow 'is the joint between the upper and lower parts of the arm where it bends in the middle'. It is connected to the bones that join the biceps. In the context of its use, the idiomatic expression connotes the act of assisting, supporting or helping others in need of help, especially financial help. The idiom can be applied to someone who needs help in the time of adversity or trouble in order to lift the problem(s) off his/her shoulders.

5. Fesè wonsè (Literarily, to match legs together but metaphorically, to be in contest with someone). This is a Yorùbá idiomatic expression which verbalizes the act of struggling with an opponent in the race for a coveted prize. The legs upon which the entire body parts rest perform a locomotive function. They are used to walk. The idiom is used to indicate that two or more people in a contest are squaring it up between or among themselves for some prize.

6. Fapá jánú (Literarily, to snap the stomach with the arm but metaphorically, to agitate for something). When this idiom is in use, the context of its usage is mostly the one which is suggestive of disdain, anger, protest and unyielding stubbornness, as, for instance, in a display of unyielding stubbornness by members of a trade union against their employers. This demonstration of protest against perceived injustice is often expressed by trade unionists, human rights activists and those associated with seeking redress for unfair treatment. It can also be used when an individual stubbornly refuses to yield or shift ground on account of indignation or anger.

7. Fowó òsi júwe ònà ilé funní (Literarily, to use the left hand to show the way to someone but metaphorically, to dismiss). In Yorùbá worldview, the left hand signifies disdain or insult. For instance, it is forbidden that the left hand is used to give or offer an item to another person. Neither is it desirable to receive an item from another person with the left hand. When the left hand is outstretched to collect a material from another person, the giver quickly withdraws his hand, because the gesture is considered in Yorùbá land as a taboo or as a token of impoliteness. The left hand too is used to decline an offer as well as to dismiss a fact. It is also used to treat a matter disdainfully. In the context of its usage, the idiom which is euphemistic in nature means to dismiss an employee from work, to humiliate by relieving a person of his/her job, or to treat another person discourteously and disdainfully.

8. Sun rárà ẹsè (Literarily, to render elegy with the feet but metaphorically, to engage in an aimless wondering). This idiom constructs a seemingly contradictory phenomenon; hence, it may seem incomprehensible to anyone who is not well-grounded in Yorùbá idiomatic expressions. For, the feet are not body organs for singing. They are far from performing a singing activity. Rather, they are used to tread the earth and perform sporting activities. But in this context, it means to wander or walk aimlessly. The idiom is used for a jobless loafer who goes about aimlessly.

9. İrowó, ìrosè (Literarrily, both hands and legs beginning to drop but metaphorically, effortlessly; easily; peacefully). The adage that two good heads are better than one is most apposite in this context. This is because what two heads (two persons) will reason out together is far more likely to produce an acceptable proposal than when a head (a person) or an individual is involved in a decision making. Similarly, when the hands and feet are involved in the execution of a task, the Yorùbá believe that the task will produce a successful outcome. Therefore, the idiom, irowó, irosè, means an effortless accomplishment of a task. It is used to refer to the outcome of a task which has produced a remarkable success, but with much less effort. For instance, an amicable settlement of a dispute in an industrial relations context or a settlement in a domestic hassle all fall within the context of this idiomatic expression.

10. Fàyà rán (Literarily, to use the chest for support but metaphorically, to persevere). The chest is believed to be the appropriate body organ that is used to lift a heavy load before the load settles on the head. In weightlifting, for instance, it is normal that while the weightlifter lifts up the weight, he first places it on his chest for him to be able to lift the object of weight aloft. So, the idiom, fàyà rán(bear burden with the chest), is an indication that the chest is an important body part that bears the burden of any kind. This is not surprising as the portion of the human body houses such vital organs as the heart, the lungs and the liver. The idiom therefore means to endure or to persevere.

\section{Idiomatic Expressions that Relate to the Internal Organs of the Body}


The internal organs constitute the vital body organs that are found inside the stomach. They help in the homeostasis of the human beings. Majority of them constitute those that human beings cannot live without. Others are less vital which implies that human beings can live without them. Some of the internal organs which constitute a veritable source of Yoruba idiomatic expressions include: the heart, lungs, stomach, kidney, diaphragm, spleen, liver, pancreas, the bile and the large and small intestines. Below are some of the Yorùbá idiomatic expressions that relate to the internal organs of the body.

1. Fèdò lóri òroǹró (Literarily, to place the liver on top of bile but metaphorically, to be at peace with someone). Both the liver and the bile are vital internal organs in the body. While the liver is edible, the bile is not, because of its bitter taste. Placing the liver atop the bile conjures a contrasting yet soothing image. The effect produced by the two organs can be likened to the contrast between water and fire, but the combination of which produces a soothing or a less hazardous effect, to a Yorùbá adage, the water quenches the ranging venom of the blazing fire. Therefore, the combination of the sweet edible liver and the bitter inedible bile paradoxically produces a soothing effect. In the context of its usage, the idiomatic expression means to maintain peace and tranquillity, especially in a dispute or in an argument. It is also used to advise someone with frayed nerves due to smouldering anger, bitterness or animosity to sheathe the sword and embrace peace. It is an idiom that is often used in a rancorous situation to advise the warring parties to temper anger with calm.

2. Fèjè sinú, tutó funfun jáde(Literarily, to conceal the blood and spit out white saliva but metaphorically, to express deception). This idiom expresses a contrasting pair. The contrast expressed in each of the NP (Noun Phrase) gives an overall effect of deception. The first segment of the NP (fèjè sinú), for instance, conjures up the image of blood with its red colour concealed within, and which sharply contrasts with (tutó funfun), that is, emit the spittle which is assumed to be white in colour. There is even a contrast between sinú (within) in the first segment of the idiom and jáde (outside) in the second segment. So, the idiom is a funny bundle of seeming contradictions. But, the seeming contradictions are not without their heavily embedded meanings. Because of the paradoxical image which the idiom conjures, its meaning is expectedly couched in protean evasiveness. The idiom is used to describe the speech or action of someone as lacking in truth, veracity and transparency. It is also used to refer to the chameleon-like proteaness in someone's conduct. Therefore, a person who is parsimonious with the truth or who says the exact opposite of his/her intention is mostly associated with the idiom.

3. Gbókàn sókè (Literarily, raise the heart aloft but metaphorically, to be agitated). The heart which perhaps is the most vital of the organs of the body resides in the left side of the chest. It pumps blood around the body. It is so sensitive and so vital to human existence that doctors often advise to treat it specially by refraining from any habit or activity that is capable of rendering it dysfunctional. Some of those activities or habits include excessive consumption of salt, alcohol and cigarettes. Again, people are advised to refrain from things that can trigger nervousness such as engaging in risky ventures which can cause nervousness and emotional instability. In the context of its usage here, the idiom connotes any action or activity that can instigate nervousness, giddiness or a state of emotional and psychological imbalance. When someone is faced with a complex and, sometimes life-threatening challenge, the tendency is that their actions may betray anxiety, restiveness and restlessness. That moment is, literally, when the heart takes a momentary flight from its natural habitat. The heart returns to its closet only when the cause or source of the trouble finally and completely disappears. The idiom is a piece of advice that no one should engage in any task that can cause the heart to suffer excessive trepidation.

4. Fèjẹ wè (Literarily, to bathe in blood but metaphorically, to be in grave danger). The blood is symbolic of danger, though it also symbolizes life. In this context, to bathe with blood is to be in grave danger. It is a cautionary statement to an indiscreet or a heedless person to desist from his/her incautious and impetuous habit. The Yorùbá adage that says, 'the dog that strays into the lion's den will get itself bathed in or soaked with its blood' is a good illustration of the idiom in this context. It is only an impetuous and imprudent person who will dare an armed soldier when he does not have any means of self defence. Therefore, any unarmed person who stupidly challenges a well-kitted person to a duel may be said to be attempting to bathe in his own blood.

5. Onifun kan bii tejò (Lietrarily, to have one intestine like that of a snake but metaphorically, A glutton). Literally, it means a person with one long intestine. Anatomically, a normal human being does not have an intestine. Rather, he/she has two loops of a long tube in the body between the stomach and the anus. The two loops are classified as the small and large intestines. This implies that a normal human being possesses two long intestines where food passes from the stomach first, from the small intestine and, finally, to the large intestine. So, possession of a single intestine by a human being constitutes physiological abnormality. The idiomatic expression above is used to describe a person whose eating habit is abnormal. It is used to describe a person with an extremely rapacious eating habit. It refers to a glutton who easily gets hungry as soon as he/she eats one round of a meal. The idiomatic expression is an adroit reference to the snake which is believed to possess a rapacious eating habit because of its possession of one long intestine.

6. Gbogbé okàn (Literarily, to receive the cut/injury of the heart but metaphorically, to be perplexed). Due to its sensitive nature as well as its centrality to the existence of every human being, the heart is often protected against any hazard to it. In this context, an incident that is capable of inflicting a serrated injury to the heart must have been a very serious one. For instance, the death of a loved one at the prime of life, dismissal from a work-place, a colossal loss or 
deferred hope is enough to cause a blistering injury to the heart. The Holy Bible underscores this fact when, in Proverbs 13: 12, it says: 'hope deferred makes the heart sick'.

7. Só sini lénu, buyọ si (Literarily, to fart in someone's mouth and at the same time pour salt in it but metaphorically, to be in confusion). To fart is to release the gas or air from the bowels through the anus. When released either silently or loudly, its offensive odour permeates the atmosphere in which it is released. When a fart is released into someone's mouth, a state of discomfort that may likely provoke puke is created. The addition of salt, however, makes the feeling all the more unpleasant and provocative. The idiom in this context describes a knotty, nasty, perplexing and confounding situation. It is used to paint a confused state of affairs. When one is faced between the devil and the deep blue sea or when one is confronted with a difficult situation where there are two unpleasant choices to make, the idiom comes readily in mind.

8. Se léegun èyin (Literarily, to break someone's backbone but metaphorically, to cut someone's source of livelihood). The backbone or the spine is an important organ in the body. It ensures body stability and virility. An injury to the spine through an accident or an infection can cause spinal cord injury. When it occurs, the victim loses mental and physical agility and thus becomes a mere vegetable. The idiom is used to describe a situation in which someone's source of power or means of livelihood has been destroyed and is thus, left with little or no hope of survival just in the same manner as a spinal cord injury victim has a very slim hope of enjoying a normal life again.

9. Fisó kínńkín bàdí jé (Literarily, to allow little fart to spoil the buttocks but metaphorically, to act foolishly). The idiom is used when someone squanders a big opportunity through sheer carelessness, lack of restraint or complete recklessness. The idiomatic expression comes in handy when there is a golden opportunity awaiting someone and one is only an inch to grab the opportunity but, owing to indiscretion and impetuosity, misses the opportunity by the whiskers. The underlying meaning in this idiomatic expression is that it is always dangerous to treat important issues flippantly because an opportunity comes but once.

10. Su sága (Literarily, to defecate on the chair but metaphorically, to stain or lose one's integrity). This euphemistic expression is a derivative of a Yorùbá expression that, igbà tóyinbó bá fẹ lo ló ń su sága, meaning that the white man defecates on the chair when he decides to take his leave (from a place). The context of usage of the idiom is when someone, especially a guest or an occupant of an office leaves an unpleasant memory in the wake of his/her exit. Expectedly, a visitor is expected to leave fond memories for his/her guests in the wake of their departure. This benign gesture is, therefore, expected of an occupant of a position of responsibility that he/she should leave behind remarkable footprints on the sand of time for his/her patrons and successors because of the popular Yorùbá belief that the rain can beat someone back into the same house from which one has taken a cover in more than one time. The implication is that one should not destroy the ladder that one has used to climb up to the top, for, the same ladder will be required when ascending. This implies that in whatever position of responsibility we find ourselves, we should demonstrate a high sense of integrity by not staining or losing it.

\section{FINDINGS/DISCUSSION}

Our findings from this study thus far showed that the Yorùbá idioms are many and varied, and treat different thematic preoccupations. Besides, they constitute an important aspect of the traditional Yorùbá orature. Rendered in great solemnity, Yorùbá idioms treasure in the expressions of almost all aspects of human activities. In other words, they are utilized to express short and compact sayings of universal relevance. As a speech genre in the linguistic repertoire of the speakers of the Yorùbá language, Yorùbá idioms express the rich and fecund facilities of the Yorùbá people from the southwest part of Nigeria. They also constitute models of verbal economy among the elders in whose mouths idiomatic expressions taste the sweetest.From the data presented in this study also, it is evident that there is hardly any part of the human body, from the external organs to the internal organs, that does not construct pithy and laconic expressions that are profound in meaning and elegant in style. They construct the collective wisdom of the elders in the society with such thematic preoccupations that are primarily meant to teach, to warn, to admonish and to build up good and noble character traits in the minds of the present generation of the youths.

Furthermore, the need to inculcate the understanding of Yorùbá idioms in the minds of the youths in the society is informed by the youths' neglect of the time-honoured cultural values of the Yorùbá norms and their unashamed preference for the foreign language and culture. This unusual preference for foreign culture, to say the least, has contributed largely to the diminishing status of the indigenous languages in Nigeria as a whole. For, according to OhiriAnichie (2014), 'many of the indigenous languages are endangered today due to neglect and denigration as over twenty five percent of children below the age of eleven are unable to speak their parents' indigenous languages' let alone deploy the fecundity of the indigenous idioms in their spoken and written expressions. Many literate Nigerian parents themselves have helped the matter either as they usually discourage their children from speaking in any other code than the English language which they regard as the language of the elite group in the society. (https://www.vanguardngr.com/2014/02/400-nigerian-indigenous-languages-endangered/ assessed Jan. 3rd,2017)

\section{CONCLUSION}


We examined in this paper the contents and values of selected Yorùbá idiomatic expressions that relate to the parts of the human body. We argued that a research into the human body should not be the exclusive study area of human anatomists and physiologists alone. Linguists and language experts as well can explore the rich linguistic resources inherent in the human body to isolate and explicate the fecund Yorùbá idiomatic expressions which can serve as a fulcrum of intellectual enquiry for the learners of the Yorùbá language, most especially the youths. Our concern for undertaking this study may not be unconnected with the dwindling rate at which the traditional Yorùbá culture, of which the idioms occupy a significant place, is being treated flippantly. It is our humble opinion that the study will go a long way to rekindle the flagging interest of the youths in Yorùbá culture as this will help in saving the Yorùbá language from impending extinction.

\section{REFERENCES}

[1] Akanmu, D. (2015). 'New Yoruba Idioms and idiomatic Expressions'. A New Mode of Expression in Political Arena. International Journal of African and Asian Studies, Vol. 9, 2015, pp.34-40.

[2] Akinmade, C.A. (2012). 'The Decline of Proverbs as Creature of Oral Expression: A Case Study of Proverb Usage among the Ondo in the South Western Part of Nigeria'. AFRREV LALIGENS: An International Journal of Language, Literature and Gender Studies. Bahir Dar, Ethiopia 1, (2), 127-148.

[3] Faniran, O.A. (2017). 'A Pragma-Sociolinguistic Analysis of Language Use of Vehicle Inscriptions and Stickers in Southwest Nigeria'. An Unpublished PhD Thesis, Department of Linguistics and Nigerian Languages, Ekiti State University, Ado-Ekiti, Nigeria.

[4] Hornby, A.S. (2000). Oxford Advanced Learner's Dictionary of Current English. $3^{\text {rd }}$ Edition, London. Oxford University Press.

[5] Hymes, D. (1962). 'The Ethnography of Speaking'. In T. Gladwin and W.C. Sturtevant (eds.), Anthropology and Human Behavior. Pp 13-53. Washington, D.C.: The Anthropological Society of Washington.

[6] Ikotun, R.O. (2011). 'Saving the Yoruba Counting System from Extinction'. Papers in English and Linguistics (PEL), Vol. 12, pp. 127-147.

[7] Lawal, A. Ajayi, B. And Raji, W. (1997). 'A Pragmatic Study of Selected Pairs of Yoruba Proverbs'. Assessed Journal of Pragmatics 27 (1997), pp. 635-652.

[8] Lawal, O.A. (2015). 'Pragmatic Use of Some Proverbs on 'Egungun' Among Yoruba Speakers'. IOSR Journal of Humanities and Social Sciences (IOSR-JHSS), vol. 20, Issue 12, Ver.II (Dec. 2015), pp. 01-06.

[9] Medubi, O. (2018). 'Proverbs and Metaphors at the Crossroads: The Example of Soyinka's The Swamp Dwellers. In Osisanwo, A, Olaosun, I. And Odebode, I. (eds) Discourse-Stylistics, Sociolinguistics and Society: A Festschrift for Ayo Ogunsiji. Ibadan: Stirling-Horden Publishers Ltd.

[10] The Holy Bible (RSV) (2008). China: Bible Society Resources Limited.(w.bible2all.com)

Bolanle Tajudeen Opoola was born in Oyo Town Oyo state Nigeria. He holds a doctorate degree in Applied Linguistics and is presently an Associate Professor of Linguistics at the Federal University Oye Ekiti Nigeria where he is the current Head of Linguistics and Languages Department and Dean Faculty of Art. He has published several known articles and books in Linguistics and Languages.

Faniran hails from Osun state Nigeria with a doctoral degree in Linguistics from Ekiti state University Nigeria. He has several publications in English and presently with King University, Ode Omu Osun State, Nigeria. 